\title{
Experience, Represent, Apply (ERA): A Heuristic for Digital Engagement in the Early Years
}

\section{Tom Lowrie}

STEM Education Research Centre, University of Canberra, Australia

Tom Lowrie is a Centenary Professor and the Director of the STEM Education Research Centre (SERC) at the University of Canberra. He has a well-established international research profile in the discipline area of mathematics education. His 20 plus year body of work has focused on the extent to which primary-aged students use spatial reasoning and visual imagery to solve mathematics problems and the role and nature of graphics in mathematics assessment. Tom is leading the Early Learning STEM Australia (ELSA) pilot, funded by the Australian Government Department of Education and Training under the National Innovation and Science Agenda.

\section{Kevin Larkin}

\section{Griffith University, Gold Coast, Australia}

Kevin Larkin is a Senior Lecturer (Mathematics Education) at Griffith University. He is a member of a number of research teams investigating: STEM education in early years education; mathematics education in primary and middle school contexts; and pre-service teacher mathematics education.

\section{Abstract}

This article presents an heuristic that underpinned the development of a range of early years applications (apps) as part of the Early Learning STEM Australia (ELSA) project (20162019). The heuristic was developed to address a range of challenges that accompany the use of digital technologies in the year before formal schooling. These include the role of digital technologies in play-based learning environments, screen time, and the importance of agency when young children are using digital technologies. In an increasingly digital world, the issue of screen time looms large as a particularly contested aspect of technology use by young children. The ELSA project responded to this challenge by developing a pedagogical framework that embedded digital technologies into context-rich, play-based STEM learning. The Experience, Represent, Apply (ERA) heuristic discussed in this article is a component 
of the project's overall pedagogical framework, and provides early years educators with the opportunity, and the know-how, to integrate digital technologies into STEM activities through intentional teaching and play-based engagement. It was evident, from educator feedback at the four days of workshops we delivered, and in other comments throughout the year long trial, that the educators were able to embrace the cyclic nature of the ERA heuristic and ensure that the time spent on the tablet (Represent) was connected to contextualised learning opportunities (Experience and Apply). Importantly, the tablets provided affordances for the children to utilise User Generated Content (UGC) to support active engagement when using the tablets.

Keywords. STEM, Early Years, design research, developmental evaluation, ELSA, play-based learning, intentional teaching, digital play.

\section{Practitioner Notes}

What is already known about this topic

- Pre-schoolers' use of digital tablets is steadily growing.

- Research has primarily explored the educational benefits from the use of tablets, but less so the association with play.

- The easy to use interface of tablets is creating new conditions for children's learning and development in pre-school settings; however, limited research into an appropriate pedagogy to integrate the tablets is available.

- Young children can engage in a range of playful activities when using tablet apps.

What this paper adds

- A further contribution to knowledge/literature about apps and play-based learning on a very large sample of young children.

- A heuristic to assist early years educators in the intentional embedding of apps in play-based environments.

- Information on how apps can be used to support the development of STEM Practices.

- The role of User Generated Content (UGC) in encouraging young children's agentic action when using the apps.

- Examples of design and of pedagogic practices that connect children's app use to non-digital experiences in preschool.

Implications for practice and/or use 
- Provision of a heuristic that early years educators can use to manage app use in preschool education.

- Apps are a part of young children's lives and their use cannot be ignored.

- An approach to the design of apps is proposed that can assist commercial app designers in building apps that foster both on app and off app activities.

\section{Introduction}

The advent of the Science, Technology, Engineering and Mathematics (STEM) agenda over the past 15 years has afforded opportunities for digital technologies to be more meaningfully embedded into learning experiences. Although these opportunities can move beyond merely finding pedagogic efficiencies within the discrete STEM disciplines to include purposeful design parameters for STEM engagement; presently, the concept of STEM remains vexed and problematic, due largely to the fact it emerged from economic and industry policy, rather than as an educational initiative to improve student learning.

Although there is a growing body of research that describes STEM more broadly than what might be characterised as: a narrow focus on the four STEM disciplines; the integration of digital technologies into these disciplines (Baran, Bilici, Mesutoglu, \& Ocak, 2016); or the integration of STEM into other learning areas such as Art (STEAM) or Medicine (STEMM), integration remains problematic (Blackley \& Howell, 2015; English, 2016; Lowrie et al., 2018). Our position, in relation to attempts to integrate STEM within the daily learning experiences of young children, argues that it is more worthwhile to focus on the practices that are common to the STEM professions, building learning opportunities from rich learning tasks, supported by digital technologies, from within and outside the four STEM disciplines (Lowrie, Leonard, \& Fitzgerald, 2018), rather than mimicking the often artificial and inauthentic attempts at integration that have characterised its use historically.

In this article we present the view that the early years (here we focus on 4-6 year olds in the year before formal schooling) are the most appropriate context to establish STEM 
Practices. Our STEM Practices framework acknowledges that such practices-the ideas, methods and values common to STEM learning—occur both within the "traditional STEM professions" (scientist, doctor, engineer) as well as in many other disciplines and fields (e.g. architect, gardener, or even surf-board designer) not normally classified as STEM professions. The philosophy of moving beyond discipline-based content is highly appropriate in the early years context as learning in this context is associated with play-based engagement and intentional teaching rather than discipline content and curriculum syllabi. Since the focus of this article concerns the implementation of STEM Practices in the early years, we will not discuss the conceptualisation of STEM Practices in depth. Those interested in further information about our description of STEM Practices are encouraged to read the following papers (Lowrie, Downes, \& Leonard, 2017; Lowrie et al., 2018).

Given that early years learning, at least in the Australian context, is not beset with discipline-specific curriculum frameworks and mandated discipline specific content, there are opportunities for play-based engagement to foster STEM learning in ways not currently afforded in formal schooling. However, the use of digital technologies that align well with the embedding of STEM Practices, requires more nuanced levels of integration when working with young children in play-based environments. Therefore, in this article, a heuristic for embedding STEM learning within the early years, incorporating a learning and engagement cycle that encourages digital engagement in ways that move beyond passive screen time, is presented.

\section{Screen Time and Digital Engagement in the Early Years}

The widespread availability of digital mobile devices has heightened the debate regarding screen time for young children. For example, in the US, a study of 350 children aged from 6 months to 4 years found that $96.6 \%$ of the children used mobile devices (Marsh et al., 2018) Research in the UK by Ofcom (cited in Marsh et al., 2018) found that $65 \%$ of $3-4$ year olds 
use a tablet, with one in five of this age group having their own tablet. Given this data, it is no longer appropriate or adequate to imagine human computer interaction (HCI) as something separate from the holistic experiences of a child; rather, it should be more rightly considered an integral part of young children's play and early pedagogical experiences (Arnott, Palaiologou, \& Gray, 2018). Radesky, Schumacher, and Zuckerman, (2015) suggest that a distinction ought to be made between 'active' and 'passive' screen time. For the purposes of this article, 'active' screen time includes activities using the tablets where children are nonsedentary (e.g. copying a dance move) or where children are directing the activities they are completing on the tablet (e.g. taking photos of their creations and discussing them using the microphone).

Miller, Paciga, Danby, Beaudoin-Ryan, and Kaldor (2017) conducted a systematic review of literature regarding young children's use of digital technologies and found that instances of prolonged screen time in early childhood education contexts were usually accompanied by directions, instructions, and interactions prior, during, and after the use of digital resources (Miller et al., 2017). Thus, a numerical measure of time on device is not sufficient to determine appropriateness of use. This more nuanced approach to evaluating screen time usage is evident in the recent discussion paper concerning digital technology use released by Early Childhood Australia (2018) where it is acknowledged that some limits need to be set for young children. However, these limits must only be considered in the context of understanding that digital technologies have a legitimate role in early learning settings.

Other research concerning digital technology in the early years has examined its role in play-based learning in terms of literacy development, the social dimensions of using digital technology, and the attitudes of early years educators towards such technology.

Radesky et al. (2015) broadly summarised the literature on the subject of app use and young children. Early findings indicated that electronic books and learn-to-read apps have the 
potential to increase early literacy skills, with interactive media promoting greater engagement in activities designed to promote learning. Interactive media use does not occur in a vacuum, and adults' own use of interactive media, as well as their interactions with children during media use, can contribute to or otherwise detract from learning and development opportunities that such media provides (Radesky et al., 2014; Roseberry, HirshPasek, \& Golinkoff, 2014). Beschorner and Hutchison (2013) suggest that tablets can be used in a multitude of ways to support teaching of emergent literacy in such settings.

The social dimension of digital technology use has been considered by, amongst others, Arnott (2016) and Hatzigianni, Gregoriadis, Karagiorgou, and Chatzigeorgiadou (2018) who are in broad agreement that two positive outcomes of digital technology use by young children are increased opportunities for both collaboration and co-operation as children participate in playful activities prompted by the technology. A primary vehicle for these outcomes are opportunities for talk as children interact with the expanded social world that digital devices can facilitate (Fleer, 2018).

In terms of educator confidence and competence in using digital technologies in the early years, Blackwell, Lauricella, and Wartella (2014) investigated the relationships between factors influencing early childhood educators' use of digital technologies. Findings indicated that successful integration of digital technologies were in part dependent on the support of educational leaders to influence educator confidence, attitudes, and willingness to use technology use in their learning contexts. Although still limited when considering the implications of digital technologies in the early childhood education context, our reading of recent literature suggests that discussions about the role of digital technologies has moved beyond the active and passive screen time dichotomy, to a richer understanding of the role of digital technologies in the early years and the relationship between digital technologies and learning beyond the screen. This article contributes to this richer understanding of early 
digital technology use by proposing a heuristic that encourages authentic connections between on and off app activities in play-based environments.

\section{STEM Engagement and Play-based Learning in the Early Years}

Many STEM-based learning programs are resource intensive, typically involving the purchase of expensive "new" technologies or re-designing learning spaces, to support the intended integration of STEM disciplines. Digital resources such as robots (e.g., Sullivan \& Beers, 2016) are often considered vehicles for promoting STEM in the early years. Unfortunately, this artefact centric approach to promoting STEM is problematic and can in fact limit the likelihood of STEM being woven into the curriculum (McClure et al., 2017). Instead, with Fleer (2018) and Bird (2017), we agree that the interaction between the digital and the non-digital in early years environments can create ideal conditions for STEM learning, without the resource intensive interventions noted earlier. From our perspective, the blending of digital technologies into the early years curriculum is most effective in contexts that remain play based. As a consequence, the notion of digital play has emerged. Bird and Edwards (2014) suggest that understanding digital play has been significant for early childhood education because "it helps educators understand technology use in the early years in terms of children's play and therefore play based learning" (p.162). In identifying the specific nature of digital play, Edwards and Bird (2017) refer back to the early work of Hutt who suggested the twin notions of epistemic (exploratory play) and ludic (symbolic or imaginative play). In our conception of play, children will use the tablets to support STEM learning in both types of play, depending on whether the tablet is encouraging an exploration (e.g. using the tablet camera to take photos of objects for later patterning work) or symbolic play (e.g. importing their own photos into the tablet and then creating their own narratives around these photos). This emerging notion of digital play is significant as it can help 
educators, who may be apprehensive about technology, understand the role of digital technologies in children's play.

Unsurprisingly, confidence in using technology is critical if educators are to support children's digital play. Edwards and Bird (2017) found that technology use is strongly related to familiarity and confidence of educators, which inform decisions about how, when, and why digital devices may be used. This presents a challenge, as educators with less familiarity and confidence with digital technologies, may struggle in determining where and how to fit digital technologies into pre-existing learning progressions. This challenge is exacerbated when one considers the dramatic rise in the number of applications available for digital devices at both the iTunes App Store and Google Play. Using the iTunes App Store as an example, as at October 2018, there were just under 280000 "educational" apps at the App Store (PocketGamer.Biz, 2018). Unfortunately, research suggests that the descriptions at the iTunes App Store and Google Play serve largely as infomercials (Larkin, 2015) and may not meet the educational needs of children in the early years.

Given the more recent research into digital play, descriptions of passive versus active screen time as a measure of educational appropriateness have become redundant. The use of digital technologies in early years settings should instead consider the play-based learning that should happen 'before' and 'after' engagement with the technology as well as the playbased leaning that occurs 'during' on screen engagement. This article describes how a pedagogically robust digital program supported learning and development in the early years, and how digital and non-digital interactions can inform, and be informed by, the learning process that young children naturally engage with in play-based settings.

\section{Contextualising the Study}

Early Learning STEM Australia (ELSA) is a research project, commissioned by the Australian Government, designed to inspire curiosity and engagement about STEM in 
children attending preschool in the year before formal schooling. The project required the development and piloting of four early learning apps for these children, as well as the creation of an app for educators and an app for families. In our project design the apps were not intended to provide stand-alone activities for the children, but rather were intentionally designed to support play-based learning consistent with the Australian framework for early years learning (Belonging, Being and Becoming: The Early Years Learning Framework for Australia, 2009).

The scope of the pilot required stratified sampling from across Australia to ensure the program was representative of the diversity within the early years learning sector. Although a pilot program, ELSA is a very large project, involving 100 early learning sites spread across all of Australia's states and territories, with participation from almost 400 educators and more than 3500 four or five-year-old children.

The development of the learning apps, and the creation of a comprehensive body of non digital resources for educators and families, is framed in this article within the aspirations of the Early Years Learning Framework (EYLF), namely: Belonging, Being and Becoming. We were very conscious to ensure that the children's experiences of STEM were consistent with the EYLF and enacted through play-based activities promoting problem-solving engagement, inquiry, experimentation and realistic investigations. The learning apps were designed to be a catalyst to encourage curiosity, cooperation, confidence and creativity in young learners. This approach is in contrast to that found in many, if not most, apps for young children that largely function as stand-alone resources. Similarly, the educator and family apps provided scaffolded support for adults to engage intentionally with children to support learning without distracting from the critical aspects of discovery and play. A New Heuristic for Digital Engagement: Experience, Represent, Apply 
The STEM Practices Framework is aligned to the notion of practiced knowledge (Bereiter, 2014); the type of knowledge characterised by both the practical know-how of the pedagogy and scientific theory. Although most of the educators in the program understood the concept of STEM Practices, when they were explained to them at the workshops, the challenges of translating the big concepts into practical action within their individual and child-driven learning environments were apparent early in the program. To address this, the heuristic "Experience, Represent, Apply" (ERA) was devised to assist in the embedding of STEM Practices in the centres. The ERA is an adaptation of an earlier pedagogical model, proposed by Lowrie and Patahuddin (2015), which described a way of designing learning opportunities in a manner aligned with how concepts are developed. The 2015 publication reports on the use of the pedagogical model with students in Year 8 and Year 11, and given our current successful experiences with early years educators, we are confident of the versatility of the pedagogical model to support learning at any stage. The ERA heuristic assists educators to incorporate STEM Practices into the range of authentic activities that they already develop and deliver in their "normal" teaching and, in a metaphorical sense, works as a bridging device between the non-digital and the digital experiences of young children. The three stages of the ERA heuristic are cyclic in nature, with the intent of each phase as follows:

Experience [E]. This is what children already know. Children's lived experiences are used as the foundation for concept development through social engagement and language. Children participate in a range of play-based, off-app experiences, that provide opportunities for them to use language in ways that connect personal experiences with new understandings.

Represent $[\mathbf{R}]$. Children play a variety of activities on the apps to engage with, and represent, various STEM concepts. These representations include creating images, interpreting pictures, visualizing and using symbols. Children have opportunities to create their own representations to use within the apps via the microphone and camera tools on the 
tablets. These User Generated Content (UGC) experiences, where young children create and import their own content into the on app activities, were considered critical for play-based learning engagement that was not disrupted by the affordances (or not) of digital-devices.

Apply. [A] Children build on their learning from the on-app activities through a range of off-app activities, guided by their educators and their families. Engagement with the visual and symbolic representatives on the app also promotes new child-centered play-based experiences.

Using this heuristic, the ELSA program provided opportunities for children to experience a concept first. This concept is then represented on the app in a play-based format. The digital experience is then followed with opportunities to apply the idea to the children's own context. By way of example, developing understandings could initially encourage children to stand in order from tallest to shortest. The on-app [R] activities scaffold the children to order objects based on seriation, including the chronological ordering of events based on time, where they play with one of the four ELSA digital characters to order a series of pictures in chronological order. They then apply what they have learned to activities off-app. For example, children can be encouraged to establish play scenarios where they can order two sets of things on an attribute, such as length, where they arrange toys in order of length and then match them to strips of cloth of similar length, used as blankets for the toys to sleep on.

To provide readers with a snapshot of the [R] phase of App One, we provide a brief description of the activities that children experience in the [R] phase of ERA. In keeping with the ERA heuristic, approximately 10 learning opportunities have been developed for the [E] and the $[\mathrm{A}]$ phases of the ERA heuristic to support each of the four on app activities described below. The number of these learning opportunities will increase as educators contribute to the database of learning opportunities as the Pilot develops. 


\section{Lunch boxes}

In this activity children are inside a cubby house and see a wide variety of foods ready to be sorted for a celebration. They are then encouraged by one of the ELSA characters to describe, using the microphone, how they have sorted their food. This encourages them to think about the variety of ways objects can be sorted. It also builds teamwork, as children are working together, sharing ideas, taking turns and explaining their sorting preferences.

\section{Photo story}

In this activity children place a series of events in chronological order. The activity stories contain photos and a verbal narrative. Four photo stories have been pre-loaded in the app, but this activity is "never ending" as children and educators can develop their own photo stories. For example, children can take photos of local events or everyday routines at the centre and upload them to the app to create a story and then narrate it. These new narratives then become available as photo album stories that other children can listen to and then recreate.

\section{Let's decorate}

In this activity children create bunting for a celebration. Children are presented with a wide selection of objects that they can use to complete a variety of patterning activities including copying, extending, fixing, and creating patterns. The culmination of the activity is the opportunity for children to create and photograph their own items that they can then use to complete patterning activities on the tablet.

\section{Let's dance}

In this activity children select the dance cubby house where they can dance with the ELSA characters. Children start playing by selecting one of the songs, created in the project, that they wish to dance to. There are three songs: Patterns All Around Us, Under the Sea and Out in the Australian Bush and each builds on the patterning activities learned earlier. An ELSA 
character teaches the children three moves for each song that the children will dance in the chorus. Children can then choose to dance with the ELSA character. Each song contains verses where children are free to dance using any dance movements they choose.

As we indicated earlier, actual engagement with the tablet is restricted to the $[R]$ component of the learning design. The $[\mathrm{E}]$ activities are intended to scaffold children's understanding, as well as encourage play-based curiosity to use the apps. In early years settings, play and engagement are child-centred, consequently, the practices that pertain to the context (the sayings, doings and relatings) need to be both acknowledged and valued. The [A] component of STEM Practices are similarly important, since the children are likely to disengage with the digital resources, at any time of their own choosing, to continue to play off app.

\section{The Heuristic as a Design Principle}

The ERA heuristic was used extensively to direct the design of the nation wide ELSA pilot program. The design phase of ELSA was undertaken by a team that comprised early years and STEM academics, digital design and coding experts, and early years practitioners not involved in the pilot. A critical pedagogical point to note here is that, although digital design and coding experts (professional app developers) were employed to code the six apps, they worked under the close and very explicit direction of the pedagogical team, led by the two authors of this paper. In this way we were able to ensure that the apps that were created "out of house" were explicitly linked to the ERA heuristic. This design process often involved very "robust" discussions between educators and app developers to ensure that the apps were pedagogically aligned to the EYLF and philosophically aligned to a play-based approach to learning. In doing so, our apps are unique in terms of a number of affordances we elicit later in this article. Our co-design approach was to develop an "Alpha version" of each app, and then the implementation into the pilot sites took the form of a second iteration of the design 
process, with the educators from those sites involved as co-designers of the activities in the $[\mathrm{E}]$ and $[\mathrm{A}]$ phases that align to the $[\mathrm{R}]$ engagement on the actual apps. In many instances, educators were also able to suggest modifications to the apps that could be incorporated into the "Beta" and "Gold" versions of the apps. In other instances, their suggestions will be incorporated into subsequent design phases for future trials. In this sense, the four days of professional development offered to educators in the workshops took the form of a contextual design "blend", with the educators being invited to design learning activities for their context using the STEM Practice Framework and the ERA heuristic. Consequently, the app constituted a resource offering a partial opportunity to "represent" STEM Practices with the expectation that these experiences would be complemented with highly contextualized off app activities. We are confident in the ability of the educators in the project to continue to complement the $[\mathrm{R}]$ activities we designed. The activities developed during the workshops, and further activities created during the year-long pilot, were curated and made available to all educators via the educator app (Figure 1). This educator app thus serves as a portal for educators to access high quality STEM activities to use with their children.

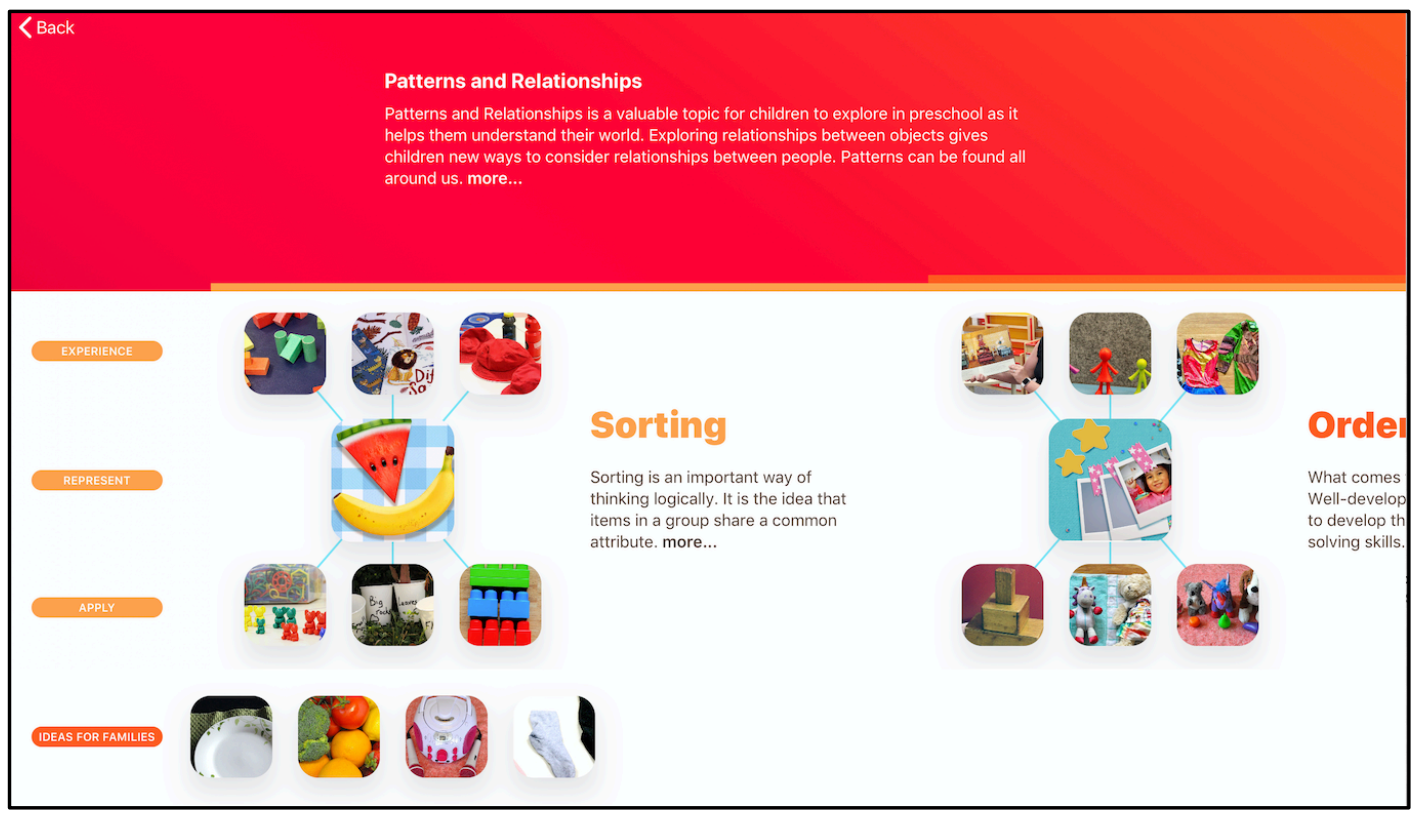

Figure 1. Educator app - curated [E] and [A] activities for app 1 


\section{The ERA Heuristic in Practice}

Although there are four children's apps in the pilot program, due to word limitations, examples from only one are used to illustrate the heuristic in practice. These examples are characteristic of the type of activities found in each of the four apps. The first children's app developed children's understandings of patterns and relationships; with such understandings critical for engagement in STEM Practices. In this app children engage with and explore four keys concepts, namely: sorting; ordering; patterning and representing. The overarching Theme of App One is "Celebrations" and the various activities children participate in on the tablet all relate to preparing for an actual celebration in the centre. The $\mathrm{R}$ activities are therefore reasonably generic, whereas the $\mathrm{E}$ and the $\mathrm{A}$ activities are to be tailored by educators to be appropriate for their individual context. In the case of sorting, the example outlined in detail below, there are suggestions as to how sorting can be incorporated in preparing for an actual celebration in the centre. In this section of the article, artefacts created initially by the project team, as well as those co-created with educators during the program, are used to demonstrate how the educators sequenced learning opportunities within the ERA heuristic to assist children with the development of understanding associated with the concept of sorting. Sorting helps children develop foundational skills associated with observing attributes and sharing information by noticing differences and similarities among objects and sharing these ideas with others.

In the [E] component of the heuristic, children were encouraged to sort familiar objects sourced from within the learning centre (see Figure 2a) or from the environment (see Figure $2 b$ ). The sorting was typically undertaken using only one attribute (e.g., colour or size or texture). 


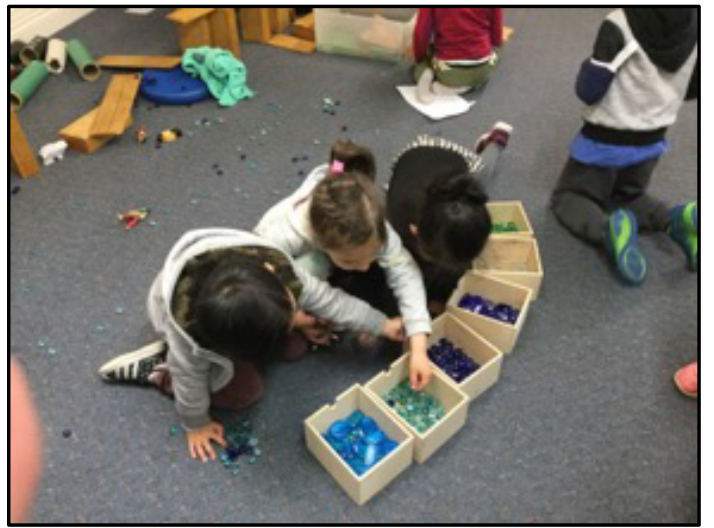

Figure 2a. Sorting objects by colour

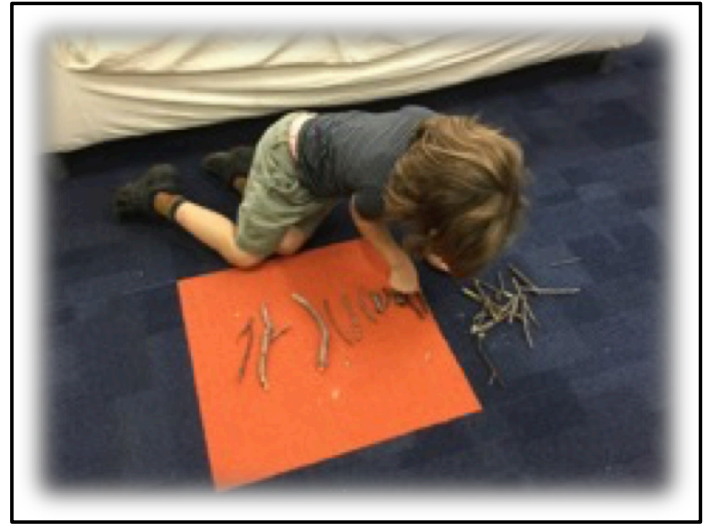

Figure 2b. Sorting objects by size

In the Represent component of the heuristic, the children help one of the four ELSA digital characters sort foods into lunch boxes in preparation for a celebration at the centre. This activity can be undertaken either individually, in pairs, or preferably in small groups of three or four children. Children are presented with a wide variety of foods for a celebration that are to be sorted into lunchboxes (See Figure 3). Once the children have completed their sort, the machine learning within the app "speaks" an educated prompt at the reasoning behind the child's sort e.g. "I can see lots of long/green/round/crunchy foods". The educational prompt is based on app coding that assigns a numerical "weight" to the various attributes associated with each object. The app evaluates the sorting that a child has done, "weights" their answers, and then provides an initial educated prompt for the reasoning behind the sort. This audio prompt serves to either reinforce the child's thinking or provoke alternate justifications. Important here is the observation that the open-ended nature of the activity affords children with the opportunity to sort by colour, size, shape, food type, or on an attribute of their own choosing. This final point is critical for play-based, child led experiences. In one preschool, for example, a child put corn and apples into the lunchbox, and then later indicated in his audio recording that he put all the foods with a core together.

Very importantly, as sorting is a highly individualistic activity, the app does not indicate a correct or incorrect response. Instead the app prompts the child to explain why they 
have sorted the food in the way that they did (Figure 4a). This means that the child is the focus of the learning and that this learning is facilitated by, but not directed by, the app. The coding of the attributes also means that the tablet can intelligently prompt a child, or several children, to discuss their sort without an educator needing to be present to observe the sorting and then guess at what the children are thinking. This frees the educator to be able to work with other children in the off app activities and means that the children using the tablets are self-directed in their play. When more than one child is playing the app, or when one child is playing using two, three or four lunch boxes, the lunch boxes are displayed in turn so that each child is able to orally record their thinking. These recordings can then be played back (Figure 4b), which often evokes further discussion from the children. In addition, the various sortings are sent to the educator app for the educator to review. The educator can then "release" the recordings so that other children can see how their friends have completed the sorts prompting further discussion about the different ways objects (in this case foods) can be sorted.

The ability for children to record their thoughts is an example of how we incorporated UGC in each of our apps. This enabled children to create their own content in the [E] phase, (e.g. photos of events in the preschool), import these into the app to play with in the [R] phase, and then share them with their friends to use in the [A] phase. Our use of UGC in early years apps is highly innovative, if not unique, and distinguishes these apps from other educational apps available for young children, which generally only supply in built, static content. Our innovative use of UGC also ensures that screen time is a highly active experience for young children using the apps. 


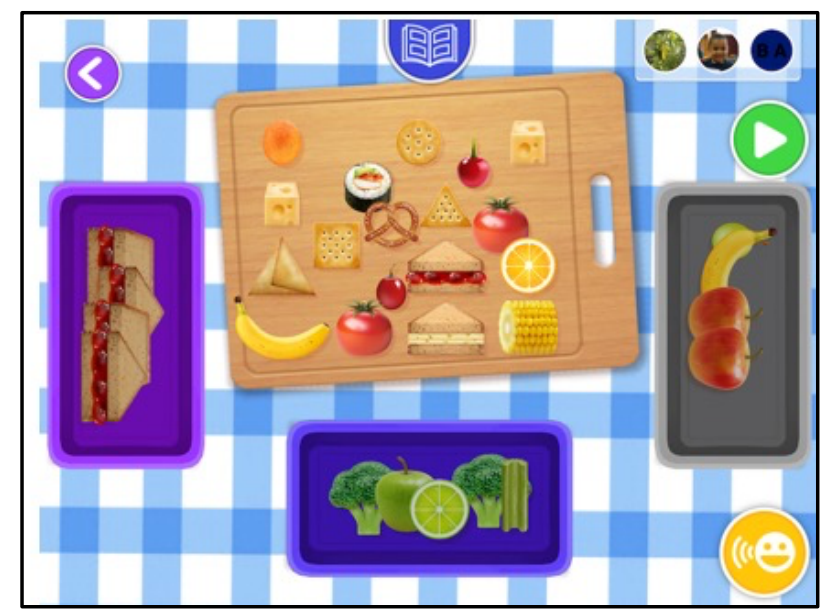

Figure 3. A screen shot of a completed sorting activity into lunch boxes

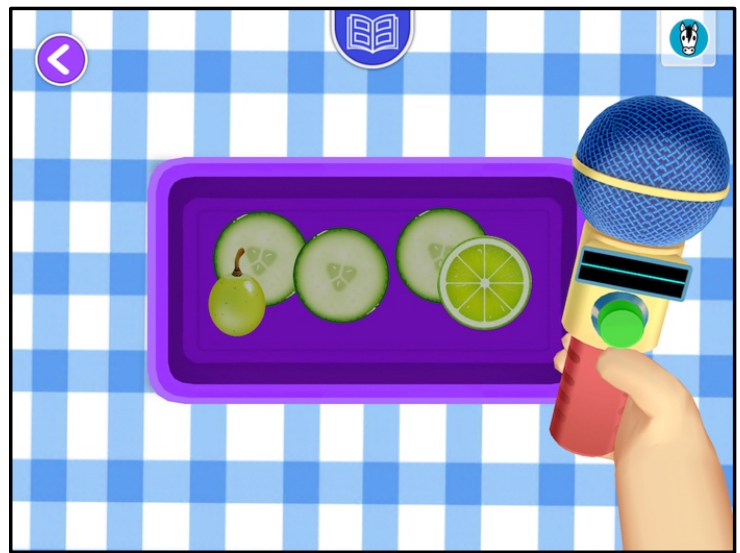

Figure 4a. UGC recording to justify sorting attribute

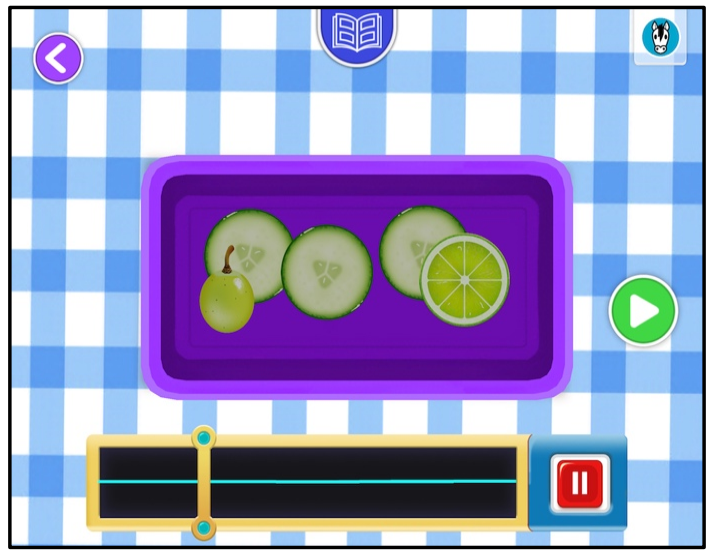

Figure 4b. UGC playback to listen to other children's propositions

In the $[\mathrm{A}]$ phase, children are encouraged to undertake more challenging sorting activities than those developed in the $[\mathrm{E}]$ and $[\mathrm{R}]$ phases. For example, children are encouraged to move beyond sorting on only one attribute. In the first instance, this involves close connections between the on-app and off-app engagement, with children taking photos (Figure $5 \mathrm{a} \& 5 \mathrm{~b}$ ) that can be used for pattern and relationship development in another activity on the app (Figure 6). Later, children are exposed to experiences that encourage them to sort by two sets of objects or attributes (e.g. size and colour). In this phase of the learning cycle, some children in the pilot worked collaboratively to sort complex assortments of objects and toys (Figure $5 \mathrm{~b}$ ) on two or more attributes. These [A] activities are examples of the affordances of the digital resources to provide scaffolding that provoke children to engage differently in their play-based physical world. The capacity to justify decisions, propose alternate 
arrangements, think adaptively and critically, and to work in teams was supported through the sequential learning design where the children could use digital representations of their creations to play with the digital ELSA characters in ways that they created and directed.
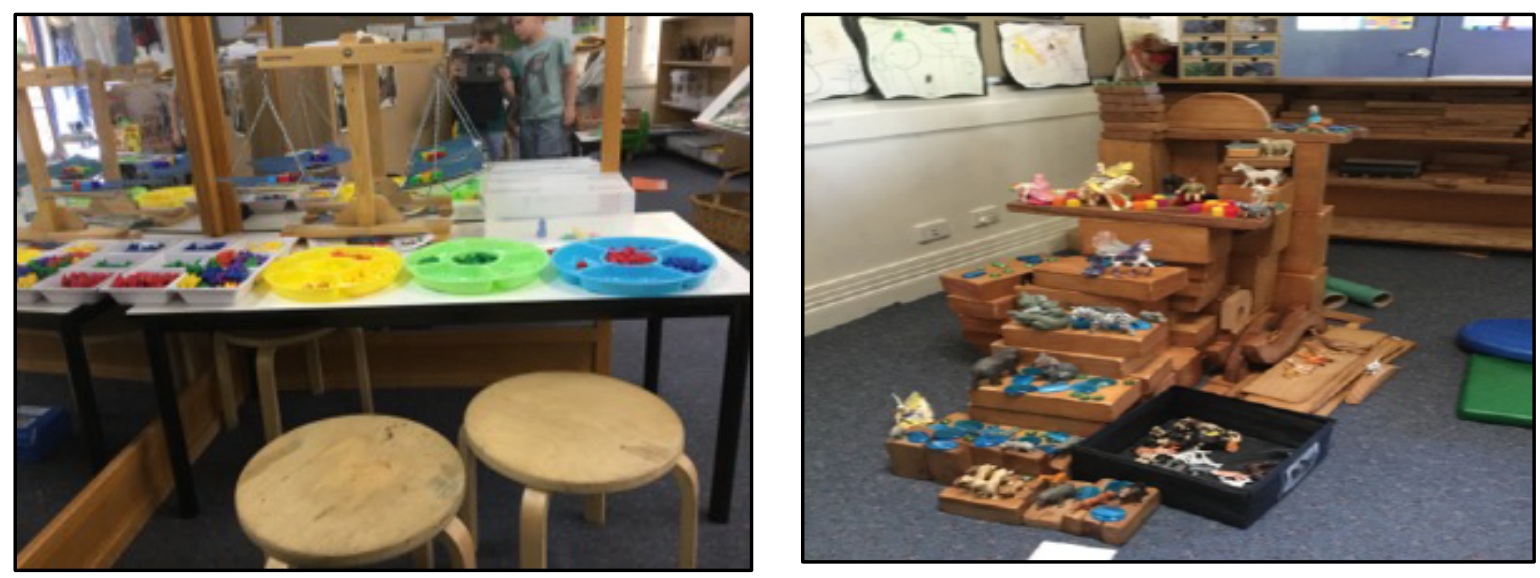

Figure 5a. Children using UCG to take Figure 5b. More complex sorting activities photos of attributes to be sorted post app engagement

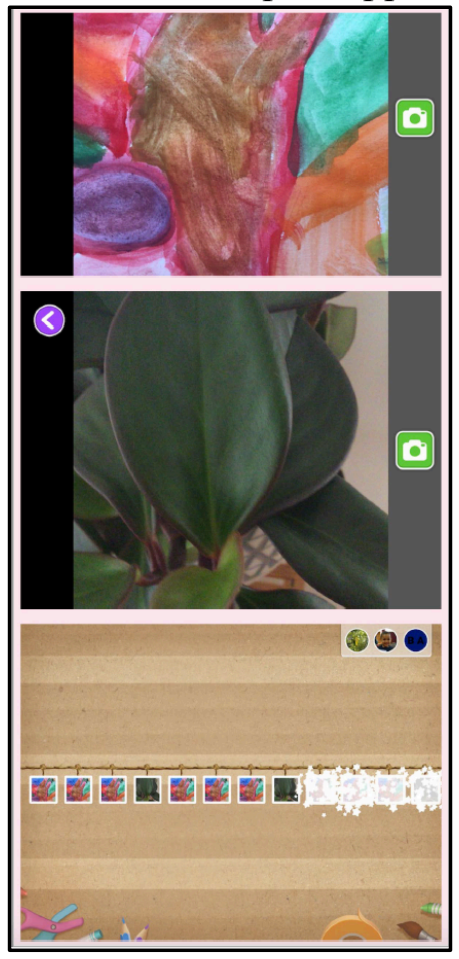

Figure 6. Children creating patterns on the app using photos they have taken.

\section{Concluding Comments}

Although we acknowledge that the notion of play could be redefined in our digital world (see Bird \& Edwards, 2014; Edwards, 2013; Edwards \& Bird, 2017), and that play involving 
digital technology needs to be examined from the perspective of children and educators (Arnott, 2016; Fleer, 2017; 2018), the purpose of this paper is not to re-define what play is via the ERA heuristic (Lowrie et al., 2018) Consequently, we do not refer to what the children are doing when using the apps as digital play but rather as play; since a digital component is not always present. We maintain that the term digital play can limit the opportunities for more holistic play when too much attention is focussed on the digital and not enough on the play.

Rather, our stance is that children play, and sometimes that play happens to involve a tablet, or the apps on the tablet, because the tool supports how the children wish to play. Our conception has always been that the apps we designed are part of the ecology of the early childhood centres (Arnott, 2016; Arnott et al, 2018), available for children to play with when they choose, much like they can choose to play with blocks or with toys or with objects on the nature table. Thus, when children are playing they might be conducting playful experiments (Ross, 2000) where they see some insects outside, use the mini microscopes on the tablet to see more clearly some aspects of the insect, then later draw the insects or pretend they are the insects. In this understanding, children naturally play and some of that play includes some digital technology to support it. More important to us in this understanding is that when children decide to use digital technology it must support their learning through play rather than limiting it (Marsh et al., 2016; Palaiologou, 2016).

We are confident that we have been successful in supporting children's play via the creation of the apps and the ERA heuristic that directs their use (Lowrie et al., 2018). Although we have not, for ethical reasons, interviewed any of the young children using the apps (Dockett \& Perry, 2011), we have received sustained positive feedback from the educators regarding their children's response to the apps. This feedback indicates that we have been successful in the creation of a program that is engaging for young children and that 
allows them to incorporate digital technology into their play. We have included below some sample quotes from educators illustrating this.

Our students have loved working through the apps - their favourite is the Lunch Box app, followed closely by Let's Decorate, which is all about creating, completing and describing patterns. (Educator One).

The children are loving the apps and other STEM experiences! Families are asking us all the time about getting the apps at home! (Educator Four).

Students have enjoyed learning activities and experiences related to the topic of 'Patterns and Relationships'. (Educator Two).

We read the Map Makers book [a picture book written and illustrated by ELSA team] and it inspired some bird's eye mapping of our preschool. This was a collaborative project that the children participated in enthusiastically. (Educator Five).

As we indicated earlier, in our view digital technology has an important place in early years, play-based, learning contexts (see also Arnott, 2016; Bird \& Edwards, 2017; Fleer, 2018) and ERA is the hub via which we deliver STEM Practices (Lowrie et al., 2017) in a play-based, intentional way. In this conception, unlike programs utilising apps (e.g. Early Learning Languages Australia, 2019), the tablet is not the hub around which all activities revolve. Rather ERA is the hub, to deliver STEM practices in a way that supports children's play and helps them to represent the learning from their play in digital and non-digital ways. In our view, digital technologies are never a substitute for play-based engagement in the physical world, nor does their use constitute a separate play experience for children. Rather, digital technologies are part of the larger set of resources (blocks, bundles of sticks, dress up clothes etc.) available for children to use as they play (Fleer, 2018; Yelland \& Gilbert, 2017). A range of anecdotal feedback from educators provides us with a high degree of confidence that the ERA heuristic is a powerful mechanism for encouraging play-based, STEM learning in ways that incorporate children's digital and non-digital experiences in authentic ways. We conclude this article with a small sample of illustrative comments from educators regarding 
the power of the ERA heuristic in assisting them to incorporate STEM in the day-to-day

activities in their centres.

Throughout the year we have continued to provide our students with a host of learning activities and experiences related to 'Patterns and Relationships', the first ELSA topic. We used the Experience, Represent, Apply method, as outlined in the educator app, with great success. Here, students get to physically experience an idea first, such as sorting things according to attributes, then they get to explore and represent that idea on an app (for example, sorting lunch boxes) and then they get to apply that understanding using different materials and resources in an authentic way. (Educator One).

We have started using app 2, however our focus has mostly been off app so far. The educators were able to support [the children] using the concept knowledge from the educator app. (Educator Five).

Regarding our off app experiences for location and arrangement today. I really didn't plan explicitly for all of these experiences, it was just that we used the ELSA positional language cards yesterday to arrange our obstacle course and found today that there was positional language in heaps of the things we were doing. (Educator Two).

\section{Ethics}

This project received ethical clearance from the University of Canberra. Informed consent was gained from parents and educators. The photos used in the article form part of the usual reporting procedures of the centres and are used with permission.

\section{Acknowledgements}

The authors would like to acknowledge the educators and young children that took part in this pilot. Findings discussed in this article are drawn from a larger data set generated in the project. There are no conflicts of interest to report for this research project. The ELSA project is funded by the Australian Government.

\section{References}

Arnott, L. (2016). An ecological exploration of young children's digital play: framing children's social experiences with technologies in early childhood. Early Years, 36(3), 271-288.

Arnott, L. Palaiologou, I., \& Gray, C. (2018). The changing nature of early childhood learning ecologies, experiences and pedagogies in a digital era. British Journal of Educational Technology, 49(5). pp. 803-806.

Baran, E., Bilici, S. C., Mesutoglu, C., \& Ocak, C. (2016). Moving STEM beyond schools: Students' perceptions about an out-of-school STEM education program. International Journal of Education in Mathematics, Science and Technology, 4(1), 9-19.

Belonging, being and becoming: The early years learning framework for Australia. (2009).

Retrieved from

https://docs.education.gov.au/system/files/doc/other/belonging_being_and_becoming the early years learning_framework_for_australia.pdf 
Bereiter, C. (2014). Principled practical knowledge: Not a bridge but a ladder. Journal of the Learning Sciences, 23(1), 4-17. doi:10.1080/10508406.2013.812533.

Bird, J. (2017). Children's responses to working and non-working digital technologies. In L. Arnott (Ed.), Digital technologies and learning in the early years (pp. 101-113), London, UK: Sage.

Bird, J., \& Edwards, S. (2014). Children learning to use technologies through play: A Digital Play Framework. British Journal of Educational Technology, 46(6), 1149-1160. doi:10.1111/bjet.12191

Blackley, S., \& Howell, J. (2015). A STEM Narrative: 15 Years in the Making. Australian Journal of Teacher Education, 40(7), 8

Dockett, S., \& Perry, B. (2011). Researching with young children: Seeking assent. Child Indicators Research, 4(2), 231-247. doi:10.1007/s12187-010-9084-0

Early Childhood Australia. (2018). Statement on young children and digital technologies. Canberra, ACT: ECA. http//dx.doi.org/10.23965/ECA.001

Early Learning Languages Australia (ELLA) (2019). Retrieved from https://www.ella.edu.au/

Education Council. (2015). National stem school education strategy: A comprehensive plan for science, technology, engineering and mathematics education in Australia. Retrieved from http://www.educationcouncil.edu.au/site/DefaultSite/filesystem/documents/National\% 20STEM\%20School\%20Education\%20Strategy.pdf

Edwards, S., \& Bird, J. (2017). Observing and assessing young children's digital play in the early years: Using the digital play framework. Journal of Early Childhood Research, 15(2), 158-173. doi:10.1177/1476718X15579746

English, L. D. (2016). STEM education K-12: perspectives on integration. International Journal of STEM Education, 3.

English, L. D. (2017). Advancing Elementary and Middle School STEM Education. International Journal of Science \& Mathematics Education, 15, 5-24. doi:10.1007/s10763-017-9802-x

Fleer, M. (2017). Digital Play: Conceptualising the relation between real, augmented, and virtual realities. In N. Kucirkova \& G. Falloon (Eds.), Apps, Technology and Younger Learners. Oxon: Routledge.

Fleer, M. (2018). Digital animation: New conditions for children's development in play-based setting. British Journal of Educational Technology, 49(5), 943-958. doi:10.1111/bjet.12637

Hatzigianni, M., Gregoriadis, A., Karagiorgou, I., \& Chatzigeorgiadou, S. (2018). Using tablets in free play: The implementation of the digital play framework in Greece. British Journal of Educational Psychology, 49(5), 928-942. doi:10.1111/bjet.12620

Larkin, K. (2015). “An App! An App! My Kingdom for An App": An 18-Month Quest to Determine Whether Apps Support Mathematical Knowledge Building. In T. Lowrie \& R. Jorgensen (Eds.), Digital Games and Mathematics Learning, 4, 251-276. Springer Netherlands.

Lowrie, T., Downes, N., \& Leonard, S. (2017). STEM education for all young Australians: A Bright Spots Learning Hub Foundation Paper, for SVA, in partnership with Samsung. University of Canberra STEM Education Research Centre.

Lowrie, T., Leonard, S., \& Fitzgerald, R. (2018). STEM Practices: A translational framework for large-scale STEM education design. EDeR. Educational Design Research, 2(1). https://doi.org/10.15460/eder.2.1.1243

Lowrie, T., \& Patahuddin, S. M. (2015). ELPSA as a Lesson Design Framework. Journal on Mathematics Education, 6(2), 77-92.

Marsh, J., Plowman, L., Yamada-Rice, D., Bishop, J., Lahmar, J., \& Scott, F. (2018). Play and creativity in young children's use of apps. British Journal of Educational Psychology, 49(5). doi:doi:10.1111/bjet.12622 
McClure, E. R., Guernsey, L., Clements, D. H., Bales, S. N., Nichols, J., Kendall-Taylor, N., \& Levine, M. H. (2017). STEM starts early: Grounding science, technology, engineering, and math education in early childhood. Retrieved from http://www.joanganzcooneycenter.org/wpcontent/uploads/2017/01/jgcc stemstartsearly final.pdf

Miller, J. L., Paciga, K. A., Danby, S., Beaudoin-Ryan, L., \& Kaldor, T. (2017). Looking beyond swiping and tapping: Review of design and methodologies for researching young children's use of digital technologies. Cyberpsychology, 11(3) doi:10.5817/CP2017-3-6

Palaiologou, I. (2016). Children under five and digital technologies: implications for early years pedagogy. European Early Childhood Education Research Journal, 24(1), 5-24. doi:10.1080/1350293X.2014.929876

PocketGamer.biz. (2018). App store metrics. Retrieved from http://www.pocketgamer.biz/metrics/app-store/

Radesky, J., Schumacher, J., \& Zuckerman, B. (2015). Mobile and Interactive Media Use by Young Children: The Good, the Bad, and the Unknown. Pediatrics, 135(1). Retrieved from http://pediatrics.aappublications.org/content/135/1/1

Roseberry, S., Hirsh-Pasek, K., \& Golinkoff, R. (2014). Skype me! Socially contingent interactions help toddlers learn language. Child Development. 85(3):pp 956-970. doi: 10.1111/cdev.12166

Ross, M. (2000). Science Their Way. Young Children, 55(2), 6-13.

Sullivan, A., \& Bers, M. U. (2016). Robotics in the early childhood classroom: learning outcomes from an 8-week robotics curriculum in pre-kindergarten through second grade. International Journal of Technology and Design Education, 26(1), 3-20.

Sweetser, P., Johnson, D., Ozdowska, A. \& Wyeth, P. (2012). Active versus passive screen time for young children. Australasian Journal of Early Childhood Education, 37(4), pp. 94-98

Yelland, N. J., \& Gilbert, C. L. (2017). Reimagining play with new technologies. In L. Arnott (Ed.), Digital technologies and learning in the early years. London, UK: Sage. 